\title{
VIOLENCIA POLÍTICA Y RESISTENCIA EN BRASIL: LA LUCHA CONTRA EL CRIMEN HERMENÉUTICO EN UNA NOVELA DE FREI BETTO
}

\section{PÍA PAGANELLI (CONICET/UNGS)}

Instituto de Desarrollo Humano- Universidad Nacional de General Sarmiento.

Juan María Gutiérrez 1150 (Los Polvorines, Pcia. de Buenos Aires)

piapaganelli@yahoo.com.ar

\section{Resumen}

El presente trabajo se enmarca en el estudio de la relación entre la Iglesia Católica y la violencia política en Brasil, en especial a partir de los años de 1960, cuando comienza a tomar forma la llamada Teología de la Liberación Latinoamericana. Frei Betto, como intelectual religioso participante de dicha corriente y víctima de la violencia de Estado en Brasil, plasmó su experiencia carcelaria en diversos relatos testimoniales en los cuales el objetivo central gravita en torno al poder militante y subversivo de la memoria individual y colectiva. En el presente trabajo el análisis de la novela Diario de Fernando, permite reconstruir los procedimientos narrativos de los cuales se vale Betto para brindarle legitimidad histórica a un relato testimonial que busca denunciar (como forma de resistencia) una versión silenciada sobre la realidad de la sociedad brasileña durante el terrorismo de Estado, a la vez que justificar las modificaciones producidas al interior de la institución eclesiástica a partir del Concilio Vaticano II (1962-1965).

\section{Palabras Clave}

Violencia Política - Memoria - Literatura Testimonial - Literatura Brasileña - Iglesia Católica

\begin{abstract}
This investigation is framed in the study of the relationship between the Catholic Church and political violence in Brazil, especially in the 1960s when it began to take shape the so called Latin American Liberation Theology. Frei Betto, as a religious intellectual who participated in that movement and was a victim of state violence in Brazil, represented his prison experience in various testimonial novels in which the main objective revolves around the militant and subversive power of individual and collective memory. In this paper the analysis of the novel Diario de Fernando, allows to reconstruct the narrative procedures that Betto uses to give historical legitimacy to a testimonial novel that seeks to report (as a form of resistance) a silenced version of the reality of society during the Brazilian state terrorism, as well as to justify the amendments made within the ecclesiastical institution since Concilio Vaticano II (1962-1965).
\end{abstract}

\section{Key Words}

Political Violence - Memory - Testimonial Literature - Brazilian Literature - Catholic Church 


\title{
VIOLENCIA POLÍTICA Y RESISTENCIA EN BRASIL: LA LUCHA CONTRA EL CRIMEN HERMENÉUTICO EN UNA NOVELA DE FREI BETTO
}

\author{
PÍA PAGANELLI (CONICET/UNGS) \\ piapaganelli@yahoo.com.ar
}

\begin{abstract}
"La literatura es uno de los recursos que he encontrado para mantener viva esa memoria (memoria de la dictadura), porque manteniendo viva la memoria, las personas saben, se indignan, ayudando a evitar que eso se repita y que la gente viva nuevamente en un período dictatorial, así como Brasil ya vivió en varios ciclos dictatoriales." 1
\end{abstract}

\section{La reconciliación posible: literatura - experiencia}

Frente a las experiencias de las dictaduras militares que acecharon al continente latinoamericano en los años sesenta y setenta del siglo XX, la reparación democrática se hizo carne en la exaltación del testimonio de las víctimas como forma de restaurar en el presente a una comunidad desgarrada por la violencia de Estado. Beatriz Sarlo ${ }^{2}$ habla de "sujeto resucitado" para referirse a la revalorización de la dimensión subjetiva que se produjo en el mundo de las ideas en los últimos años, por oposición a la muerte del sujeto sostenida por el estructuralismo años anteriores.

Este resurgimiento de la figura del testigo tiene como centro gravitatorio a la experiencia histórica de Auschwitz que deviene símbolo testimonial, e inicia el debate en torno a la memoria y a la posibilidad de testimoniar lo "indecible". Enzo Traverso ubica la emergencia de la figura del testigo en 1961, año del proceso de Eichmann en Israel, cuando se mira al testimonio como un proceso terapéutico donde el que logró volver pudo relatar su historia. ${ }^{3}$ Annette Wieviorka también señala dicho período como la "era del testimonio"4 que se reproduce en mayor escala en la década del ochenta y noventa, hipótesis que también defiende Elizabeth Jelin, ${ }^{5}$ por oposición a Esther Cohen, ${ }^{6}$ quien señala la emergencia del testigo a fines de los años setenta.

En América Latina, Hugo Achugar sostiene que la institucionalización del testimonio se produce en los años sesenta luego de la Revolución cubana, que reconoce el lugar legítimo del testimonio

\footnotetext{
${ }^{1}$ Entrevista con Frei Betto concedida a Anita Gonçalves Hoffman durante el 2do Encontro de Ciência y Tecnologia de Paraná, realizado en Guarapuava en octubre de 2008

2 Sarlo, Beatriz, Tiempo pasado, Buenos Aires, Siglo XXI, 2007.

3 Traverso, Enzo, La historia desgarrada. Ensayo sobre Auschwitzy los intelectuales, Barcelona, Herder, 2001. Karl Adolf Eichmann fue Teniente Coronel de las SS nazi y responsable directo de la Solución Final, principalmente en Polonia, y de los transportes de deportados a los campos de concentración alemanes durante la Segunda Guerra Mundial. Fue sometido a juicio en Israel en 1961, en el que alegó en su defensa que las acciones que cometió eran bajo la obediencia debida a sus superiores y que estos se aprovecharon de esta característica. El juicio finalizó el 15 de diciembre de 1961 con la condena a morir en la horca por crímenes contra la humanidad. Este juicio también es considerado como la gran causa nacional del Estado de Israel.

${ }^{4}$ Wierviorka, Annette, L'ere du temoin, Paris, Hachette, 2002.

${ }^{5}$ Jelin, Elizabeth, "Historia, memoria social y testimonio o la legitimidad de la palabra", en Iberoamericana. América Latina - España - Portugal No. 1. Volumen 1, 2001.

${ }^{6}$ Cohen, Esther, Los narradores de Auschwitr, México, Fineo y Limond, 2006.
} 
en la lucha por el poder dentro de la esfera pública. ${ }^{7}$ Así, se abre una nueva perspectiva que permite reconciliar experiencia y relato a partir de la proliferación de relatos "no ficcionales" como testimonios, memorias, autobiografías, entrevistas autobiográficas y relatos identitarios.

Por lo tanto, la dimensión testimonial marca la forma del relato a partir de la segunda mitad del siglo XX, el cual recupera su carácter político y social al convertirse en un acto de justicia individual que interpela al mismo tiempo a una "comunidad": "Un movimiento de devolución de la palabra, de conquista de la palabra y de derecho a la palabra se expande reduplicado por una ideología de la "sanación" identitaria a través de la memoria social o personal".

Sin embargo este optimismo posmoderno puesto en la subjetividad, abre un nuevo problema, en tanto frente a la multiplicación de relatos subjetivos se destierra una Verdad unívoca y entran en crisis otros discursos como el histórico, que se diferencia del relato de la memoria por una operación de interpretación y distancia crítica del pasado, mientras que la primera supone una participación emotiva y siempre de alguna forma incompleta y tendenciosa. De ahí que al legitimar el relato subjetivo por su valor ético y moral frente a violentas políticas de silenciamiento, se instaura la problemática respecto de su legitimidad histórica e intelectual, lo cual ha vuelto a la memoria, como relato del pasado, un fetiche de la Posmodernidad.

El problema entonces es el valor de Verdad que adquiere, en el presente, el testimonio de las víctimas de la violencia de Estado frente a la necesaria instauración de regímenes democráticos fundados en principios de reparación y justicia: "la memoria como tarea colectiva es esencialmente una acción política que sólo puede realizarse si hay un espacio público que fije los criterios de realidad al someter la narración a la posibilidad de ser refutada". 'Entonces, ¿es el testimonio de las víctimas por sí sólo una fuente legítima de conocimiento del pasado?

Así, se plantea el eje central del presente estudio, a saber, las articulaciones textuales que asume el relato testimonial de Frei Betto para franquear esta dualidad entre Verdad y Ficción. Ya que no basta con pensar los relatos testimoniales como géneros autobiográficos o historiografías, sino por el contrario, reflexionar sobre su peso simbólico y la relación que entretejen entre lo "real", la imaginación y los conceptos. Tal como sostiene Elizabeth Jelin, todos los testimonios son procesos de construcción social subjetiva que hacen difuso el límite entre realidad y ficción, por tanto, el eje de la consideración fáctica se desplaza a la narrativa subjetivada.

Entones, antes que centrarse en la veracidad de lo narrado cabe hablar de "efecto de realidad" o de ilusión de "relato completo" que hace de la persuasión, procedimiento fundante de la escritura testimonial. Esta posibilidad de crear un relato "completo" se entiende a partir de la idea que sostiene Arendt ${ }^{10}$ respecto de que el testimonio se cimienta en un lazo social de confianza, que en situaciones de violencia extrema permite reconstruir un espacio comunitario de reconocimiento y duelo, que no sólo rearticula una experiencia individual sino que crea marcos reconocibles por el interlocutor al reconstruir de diversas maneras un clima de época.

En el presente trabajo se aborda el relato testimonial de Frei Betto, Diário de Fernando. Nos cárceres da ditadura militar brasileira, ${ }^{11}$ que gira en torno a su experiencia carcelaria durante la dictadura militar brasileña, a partir de una doble inflexión: lo testimonial y lo documental, como una forma de la articulación entre literatura y experiencia. De esta manera, por un lado se observan los procedimientos narrativos que buscan legitimar su relato, mientras que al mismo tiempo permiten reconstruir en su obra el clima ideológico de la época, a través de un filón de pensamiento clave de los años sesenta y setenta en América Latina como lo fue la Teología de la Liberación: la

\footnotetext{
7 Achugar, Hugo, "Historias paralelas/historias ejemplares: la historia y la voz del otro", en Revista de Crítica Literaria Latinoamericana $\mathrm{N}^{\circ} 36,1992$, pp. 51-73.

${ }^{8}$ Sarlo, Beatriz, Tiempo pasado, op. cit., p. 50.

${ }^{9}$ Zubieta, Ana María (comp), La memoria. Literatura, arte y política, Bahía Blanca, Ediuns, 2008, p. 9.

${ }^{10}$ Arendt, Hannah, Eichmann en Jerusalén. Un estudio sobre la banalidad del mal, Barcelona, Lumen, 1999.

${ }^{11}$ Betto, Frei, Diário de Fernando. Nos cárceres de ditadura militar brasileira, Rio de Janeiro, Rocco, 2009.
} 
manera en la que ingresa en los relatos ya sea en forma de reflexiones del narrador, ya sea a partir de la inclusión de documentos de la época; o finalmente, en la propia estructura narrativa.

\section{La relación Iglesia - Estado militar en Brasil}

La Iglesia Católica en Brasil representa un caso paradigmático dentro de América Latina, pues no sólo es la Iglesia Católica más extensa del mundo sino que también es en donde se esbozan las primeras modalidades que asumió la Iglesia latinoamericana en su "opción preferencial por los pobres" a partir de los años setenta específicamente, gracias a los trabajos realizados en la zona del Nordeste. ${ }^{12} \mathrm{Al}$ mismo tiempo se trata de una Iglesia en donde la Teología de la liberación ha tenido mayor influencia y donde ha impactado en la conformación actual de varios movimientos populares surgidos de los movimientos de comunidades de base cristianas: la Confederación Sindicalista Radical (CUT), el Movimiento de Campesinos Sin Tierras (MST), la Asociación de Barrios Pobres, el Partido de los Trabajadores y la Coordinación Nacional de Movimientos Populares.

Carlos Alberto Libanio Christo ingresó en 1966 en la Orden de los Dominicos ${ }^{13}$ de la Iglesia Católica -uno de los mayores centros de producción del cristianismo liberacionista en Brasildonde estudió filosofía y teología, fue ordenado Frei y adhirió a la teología de la liberación. Su participación política primero como laico y luego como religioso resulta un paradigma de la participación de numerosos religiosos brasileños durante el período más álgido de represión en Brasil, entre 1969 y 1973, luego de la sanción del Acto Institucional número cinco (AI-5). ${ }^{14}$

En 1968, decretado el citado Acto Institucional, Frei Betto viajó hacia Rio Grande do Sul invitado por el líder de la agrupación revolucionaria Alianza Libertadora Nacional, Carlos Marighella (1911-1969), ${ }^{15}$ para colaborar con la fuga de presos políticos hacia Uruguay y Argentina. Por este accionar, fue condenado en 1969 a cuatro años de prisión, iniciando su carrera literaria con la publicación de las cartas intercambiadas con familiares, editadas en Italia y

\footnotetext{
${ }^{12} \mathrm{La}$ Teología de la Liberación latinoamericana recuperó por un lado la discusión teológica desarrollada en Europa contra las concepciones no científicas del mundo y del hombre (nutrida por disciplinas como la sociología y la psicología) las cuales repercutieron en el Concilio Vaticano II (1962-1965) gracias a la impronta progresista del pontificado del Juan XXIII, y por otro, el trabajo directo con los marginados del continente. Se caracterizó por su vuelta al trabajo pastoral y por su manifiesta "opción por los pobres". Recuperó, entonces, la tradición del pensamiento social cristiano del siglo XIX pero fundó en América Latina una nueva cultura religiosa de aspiración universal, nutrida de la religión y la organización popular, de fuerte impronta anticapitalista y claras apropiaciones de las categorías marxistas en sus análisis teológicos.

${ }^{13} \mathrm{La}$ especificidad de la predicación dominica fue acercar el Evangelio a los pobres. Dios no ha creado a nadie para vivir en la pobreza y en la miseria. "Ser una Iglesia de menos poder y más servicio", sería la clave del aporte de la Orden de Predicadores a la Iglesia, según Frei Betto. "El Papa habló de que no hay que buscar el poder en la Iglesia tomando como ejemplo a Sto. Domingo. Una Iglesia servidora del mundo y de los pobres y excluidos", acotó.

${ }^{14} \mathrm{El}$ Acto Institucional Número 5 estableció el receso del Congreso, la intervención en los Estados y Municipios, la suspensión de derechos políticos de cualquier ciudadano, la suspensión de la garantía de habeas corpus, el estado de sitio, la confiscación de bienes y la exclusión de cualquier apreciación jurídica de todos los actos practicados de acuerdo con dicho Acto Institucional. A partir de ese momento, el poder ejecutivo pasó a ser ejercido por una Junta Militar, abriendo el período más oscuro y violento de la historia de Brasil.

15 En un contexto de represión militar cada vez más agudo y debido al impacto de la Revolución cubana, se radicalizaron las organizaciones de izquierda. Los tres movimientos de izquierda más importantes en Brasil fueron: las Ligas Campesinas, la resistencia nacionalista de Brizola, y la Acción Libertadora Nacional (ALN) de Carlos Marighella. Este último surgió a partir de la escisión producida dentro del Partido Comunista Brasilero en 1967 a causa del debate entre una resistencia pacífica a la dictadura y una resistencia armada. De esta última opción surgió la Acción Libertadora Nacional (ALN) dirigida por Carlos Marighella y Joaquim Camara Ferreira que defendía a la guerrilla como nueva organización de vanguardia y fue el principal representante de la línea castro-guevarista en Brasil, aunque en este caso, defendía una guerrilla inicialmente de tipo urbana para acumular recursos necesario para el traslado a la zona rural.
} 
lanzadas en Brasil, en 1974, bajo el título de Nos Subterrâneos da História (mas tarde, reeditado como Cartas da Prisão).

Este episodio, denominado "Operación Batina Blanca", es el mejor ejemplo del conflicto que se generó entre Estado e Iglesia (último bastión de resistencia anti-dictadura) frente al compromiso de los católicos de izquierda en organizaciones clandestinas durante la dictadura militar implantada en 1964. La Operación "Batina Branca" buscaba ejecutar a Marighella, pero especialmente neutralizar definitivamente a la jerarquía católica para perseguir al resto de los grupos de izquierda cristiana altamente politizados en aquella época. La derecha católica estaba directamente involucrada en el caso como proveedora de consejeros y auxiliares a la policía. El episodio involucró a 11 frades dominicos, dos padres seculares y un jesuita, mientras que toda la orden de los dominicos fue acusada de tener vínculos con las organizaciones de la guerrilla urbana.

Finalmente, el 15 de septiembre de 1971 el tribunal militar condenó a tres dominicos a cuatro años de prisión, a otro a seis meses, absolvió al resto y no se pronunció sobre la culpabilidad de Frei Tito de Alencar, quien fue cambiado por un embajador secuestrado por guerrilleros urbanos, luego de intentar suicidarse. Cuando el régimen verificó que era imposible neutralizar a la jerarquía - a causa, principalmente, del apoyo que el Vaticano dio a los prisioneros- el asunto fue olvidado. Tuvo sin embargo, una consecuencia trágica: Frei Tito de Alencar, que dentro de la prisión intentó suicidarse para escapar a las torturas, se ahorcó en un árbol en el jardín del convento francés que lo acogió luego de su liberación.

\section{Literatura y memoria como formas de resistencia}

La primera producción literaria de Frei Betto parece inseparable de su experiencia política, ${ }^{16}$ por lo que la escritura se pone al servicio de la reconstrucción de una memoria que a la vez que es individual responde a una tragedia colectiva y diseña las diversas instancias de un mismo viaje: cautiverio, libertad, escritura.

Adentrarse en Diário de Fernando - Nos cárceres da ditadura militar brasileira luego de la lectura de sus libros anteriores dedicados al drama de la dictadura militar brasileña, es como ingresar en la obra de un biógrafo que en cierto momento del relato llega a identificarse con su biografiado. En este libro, Betto se encarga de ficcionalizar los diversos fragmentos del diario de cárcel de su compañero Frei Fernando, durante los años en que ambos que fueron prisioneros por la causa "Operación Batina Blanca". Si bien una introducción y un epílogo encuadran al relato y recuperan la voz en primera persona de Frei Betto, a lo largo de la narración el testimonio de Frei Fernando de Brito se diluye en el testimonio de Betto, generando así la tesis que recorre gran parte de la obra de este último: la identificación entre todos los hombres, víctimas, oprimidos por un sistema violento e injusto.

Esta ficcionalización de elementos testimoniales pone en escena una problemática mayor, a saber, aquella que debate la relación entre realidad y ficción, entre experiencia y literatura. Más aun cuando aquello testimoniado y que se presenta con status de valor histórico y político ("documento, inédito, de inestimable valor histórico" define Betto al diario) se trata de una denuncia del carácter coercitivo y represivo de un Estado militar que se sostuvo gracias a una sistemática supresión y silenciamiento de documentos oficiales, pretendiendo erigir una memoria

\footnotetext{
${ }^{16}$ En torno a su experiencia carcelaria durante la dictadura Frei Betto construye su obra literaria inicial. Valen como ejemplos sus obras Cartas da prisão, Rio de Janeiro, Editora Civilização Brasileira,1974; Das catacumbas, Rio de Janeiro, Civilização Brasileira, 1976; A Vida suspeita do subversivo Raul Parelo, Rio de Janeiro, Civilização Brasileira, 1979 (Reeditado bajo el título de O Aquário Negro, Rio de Janeiro, Difel, 1986); Batismo de sangue, Os dominicanos e a morte de Carlos Marighella, Rio de Janeiro, Civilização Brasileira, 1982 y O dia de Angelo P., São Paulo, Brasiliense,1987.
} 
del olvido y del perdón que aún no logra en América Latina, que la sociedad salde su compromiso con el pasado. ${ }^{17}$

Sin embargo, en estas producciones literarias de Betto la tensión entre verdad y ficción pone en escena la misma ambigüedad que sostuvo al sistema represivo, la misma proliferación de discursos contrapuestos y silenciados que construyeron un tipo de verdad, una historia oficial, que Betto pretende socavar. De esta manera, al empoderar a las víctimas de su pasado, al darles VOz, al literaturizar sus experiencias, construye una denuncia contra el silenciamiento oficial en pos de una memoria colectiva, activa y militante: "Objetividad y subjetividad son aquí caras de una misma moneda, la del precio que se paga para que la memoria de las víctimas se torne, en la historia de la humanidad -como quería Walter Benjamin- perene y subversiva". ${ }^{18}$

El relato se estructura en diez capítulos definidos por desplazamientos espaciales. Así, la pasividad de la vida en prisión se contrapone en la narración con el desplazamiento incesante al que la dictadura militar sometió a los presos políticos con el fin de debilitarlos, una maniobra más de tortura psicológica. Trasladados entre noviembre de 1969 y enero de 1973 (período que aborda el relato) a cinco centros de detención diferentes, el diario de Fernando evade marcaciones temporales precisas (sólo en casos de episodios muy concretos y trascendentes como la desaparición de Frei Tito) y la profundización en cuestiones de índole íntimo y personal, para convertirse en un gran diario de la intimidad colectiva bajo la dictadura militar. No se asiste a la intimidad individual propia de un diario ni, a diferencia de la obra autobiográfica de Betto, a reflexiones religiosas o teológicas.

En este caso, las anotaciones de Frei Fernando se ofrecen como excusas para exponer a todas las víctimas que circularon por el submundo carcelario, de torturas y detenciones, durante la dictadura militar: el derrotero de presos políticos, las noticias más relevantes de la época, los vaivenes de la Iglesia Católica en relación al régimen militar y las repercusiones internacionales de la represión en Brasil. La vida en la prisión se vuelve metáfora de la vida de todos los brasileños durante la dictadura militar. El enclaustramiento y la desorientación temporal y espacial reproducen el clima de terror y censura de la época de represión. De ahí el subtítulo aclarativo: se trata de un diario sobre la vida en la cárcel, sobre la vida durante los años más cruentos de la dictadura militar, a partir de la sanción del AI-5.

La estructura narrativa recupera, como toda la obra de Betto, la fragmentariedad que puede atribuirse a la censura, a un tipo de escritura clandestina dentro de la prisión, pero también a la posibilidad concreta del recuerdo: "Antes de la mudanza quemé unas cuantas hojas de este diario. Las quemé con dolor, rabia, con un esfuerzo supremo de desapego, consciente de que allí la historia se volvía cenizas". ${ }^{19}$ En la tensión censura-olvido que pauta el ritmo del relato, Betto construye una narración sobre el valor de la palabra como resistencia frente a episodios

\footnotetext{
${ }^{17}$ En este sentido se instala la vigencia de su literatura, en el único país que atravesó una dictadura en América Latina y nunca juzgó los crímenes de Estado cometidos en esa época y en el cual recién en noviembre del 2011, bajo el gobierno de Dilma Rousseff (también víctima de la dictadura militar), fue creada la Comisión Nacional de la Verdad y la Ley de acceso a la información que regula el acceso a los documentos públicos en los ámbitos federal, estadual y municipal para investigar los crímenes de lesa humanidad cometidos durante los veinte años de dictadura militar. La importancia de esta medida viene a morigerar una relación deficitaria de Brasil con su pasado reciente, mantenida gracias a la Ley de Amnistía sancionada en 1979 durante la dictadura militar y sostenida durante la democracia que concedió el derecho de retorno a Brasil a los políticos, artistas y demás brasileros exiliados y condenados por crímenes políticos, pero también habilitó la impunidad de los represores que nunca debieron declarar ante la Justicia por sus abusos. En consecuencia, todavía resta mucho por hacerse, en tanto la Comisión de la Verdad se propone investigar las violaciones a los derechos humanos cometidas desde 1964, pero no responsabilizará criminalmente a sus autores amparados por un marco legal que va en contra de los compromisos nacionales e internacionales que ha adquirido el gobierno para defender los derechos humanos.

${ }^{18}$ Betto, Frei, Diário de Fernando..., op.cit., p. 14. La traducción de los fragmentos de la novela nos pertenece.

${ }^{19}$ Betto, Frei, Diário de Fernando..., op.cit., p. 63.
} 
inenarrables por su dramatismo, al mismo tiempo que reflexiona sobre la impotencia del lenguaje. No en vano se piensa en paralelo al episodio del Holocausto:

"Las palabras ya no son suficientes; como el pabilo separado de la bomba, por más que lo quememos, imposible hacerla explotar. A pesar de nuestro esfuerzo, las raras palabras nos traicionan [...] Tal vez la distancia entre nuestra indignación y la impotencia de los gestos sea la principal causa de la ruptura interior que sentimos [...] ¿En qué pensaban los judíos encerrados en los campos de concentración, conscientes de que en cualquier momento serían asfixiados en las cámaras de gas? Tal vez en nada, como muchos aquí ahora. Quien sabe permanecían callados y sordos, a la espera, no de la muerte o del milagro de escapar, sólo a la espera, incapaces de razonar sobre lo irracional o sentir miedo frente a lo inevitable." ${ }^{20}$

La palabra no da cuenta de lo irracional, pero aun así se escribe. ¿Por qué? Parecería ser que el objetivo final de la obra de Betto es demostrar el valor político del relato como constructor de memorias traumáticas. Por eso, siendo religioso, se pregunta en el epílogo que cierra el libro, sobre el problema de la Fe frente a la experiencia de los genocidios. ¿Cómo creer en la existencia de un Dios frente a tanto dolor humano? ¿Cómo y para qué escribir frente a tales tragedias? Betto recurre a las obras de Bonhoffer y Primo Levi, que sostienen la debilidad e impotencia de Dios, para contraponer su posición sustentada en Kierkegaard y Schelling, quienes explican el libre albedrío del hombre frente a la divinidad. Por ello, el valor de la Fe reside en la superación del Mal en tanto seres finitos que somos, y dicho aprendizaje sólo puede lograrse reparando el pasado en el presente y con miras a un futuro: "Olvidar la muerte, pretender matarla, despreciarla como a un cadáver retenido bajo piedras en el fondo más oscuro de los océanos, es sumar al crimen físico el crimen hermenéutico. Las abominaciones no prescriben y, a pesar de que todos los archivos hayan sido incinerados, la injusticia cometida exige reparación." ${ }^{21}$

Frente a este imperativo de reparación, se exige que el relato que fusiona diversas escrituras del yo (biografía, autobiografía, testimonios, diarios, cartas), presente cierto grado de verosimilitud que le brinde legitimidad histórica y política. Esto debe sustentarse a través de ciertos procedimientos que exceden las características de un diario íntimo. Los dos procedimientos fundamentales de los que se vale Betto para brindarle legitimidad histórica a lo narrado son la inserción de otras voces dentro del registro del narrador y el uso de la nota al pie. La inserción de otras voces se produce a través de la incorporación de fuentes primarias en medio de la narración, destacadas con el uso de bastardilla. Dichas fuentes son en su mayoría cartas de denuncia de los religiosos, escritas dentro de la prisión pero que tomaron estado público, y que un lector interesado podría rastrear en los diarios de la época, en las que se denuncia la tortura de Frei Tito y las precarias condiciones de salubridad carcelaria, motivo por el cual realizaron una famosa huelga de hambre en 1972 que duró 33 días. Se asiste nuevamente a otro género recurrente en la obra de Betto: el género epistolar. Claramente en textos dentro de los cuales el diálogo brilla por su ausencia, dato sintomático.

Si bien las cartas aparecen reproducidas en su totalidad, el relato también repone fragmentos de otros documentos como el de la Asamblea de obispos de San Pablo, el Manifiesto de artistas e intelectuales en apoyo a la huelga de hambre de los prisioneros, declaraciones públicas de personalidades como el obispo Dom Helder Cámara y Dom Pedro Casaldáliga, testimonios de presos torturados y la carta de Betto al teólogo Alceu Amoroso Lima explicando la postura de los presos políticos frente a la huelga de hambre. Otra voz que se presenta y que reubica al lector dentro de los cánones de la ficción literaria frente a tan marcado afán de verosimilitud, es la inserción de una crónica (género también relacionado con cierta búsqueda de lo "real") de Betto sobre la lucha entre prisioneros y carceleros. Este recurso también reaparece con insistencia en la obra de Frei Betto, no para restarle valor documental al relato sino para recuperar la tensión antes

${ }^{20}$ Betto, Frei, Diário de Fernando..., op.cit., p. 78.

${ }^{21}$ Betto, Frei, Diário de Fernando..., op.cit., p. 278. 
mencionada entre historia y literatura. Así, el efecto de realidad se funda también en una fuerte presencia de la oralidad, como sostiene Achugar. ${ }^{22}$ La persuasión se logra en la medida en que existe una credibilidad asociada a la huella de la oralidad, a través del registro de la voz del otro, pacto esencial en el testimonio.

La literaturización aparece claramente a partir de ciertas inclusiones que no responden a la estructura propia de un diario íntimo. Por ejemplo, la narración biográfica, como flash back, de la formación política de Frei Fernando hasta su detención y vinculación con el asesinato de Marighella; luego ciertos elementos de la (auto)biografía política de Frei Betto y de Frei Tito, e incluso la inclusión del testimonio de Frei Tito luego de ser brutalmente torturado (testimonio que tomó estado público y tuvo gran repercusión en la prensa internacional). Estas biografías dentro de biografías y testimonios dentro de testimonios, se reproducen a nivel macro textual través de la alternancia en la voz del narrador que se desplaza de la primera persona del singular a una primera persona del plural inclusivo, reproduciendo el juego que plantea Betto entre la figura del autor y la del narrador. Así, la historia individual, en tanto memoria individual, se entreteje con otras para conformar el entramado de la memoria colectiva, y frente a esto, la importancia de la palabra escrita como soporte fundamental de la memoria frente a la disipación de la oralidad:

“Tito narró lo que sufrió. El colectivo le pidió que escribiera su relato. Todos haremos copias para divulgar como podamos. Betto se comprometió a tomarle la declaración. Carlos Eduardo Pires Fleury y el médico Davi Unovich sugieren que los frailes sean más activos en desenmascarar la farsa de nuestro encarcelamiento. No tenemos otro recurso que las cartas, y del lado de afuera, circulares mimeografiadas" 23 .

En segundo lugar, el insistente recurso de la nota al pie se utiliza para evidenciar la manipulación de información llevada a cabo por el discurso oficial sobre el derrotero de los presos políticos, cuyas historias se mencionan en el cuerpo del relato. De hecho, si bien el diario de Fernando culmina con la liberación de los religiosos en octubre de 1973, una nota al pie se encarga de describir la trayectoria de sus vidas hasta la actualidad, al igual que sucede con el resto de los presos políticos. De esta manera, la nota al pie pretende socavar el discurso oficial, vale como ejemplo la nota 17 en la que Frei Betto, en primera persona, reconstruye su versión de la desaparición de un preso y sostiene: "En principio, encaro con desconfianza y cautela la versión oriunda de nuestras Fuerzas Armadas". ${ }^{24}$ Así, la nota al pie demuestra el derrotero real de esas personas, expande historias individuales, desmiente suicidios y sostiene asesinatos, desapariciones y exilios forzados, a través del uso de fuentes primarias como diarios y libros de investigación, que demuestran investigaciones e información recabada posteriormente a la dictadura.

El delegado Fleury, representante de los servicios de seguridad y famoso por su sanguinarias técnicas de tortura, aparece en las notas al pie en las cuales también se explicitan los diversos tipos de torturas (pan de arara, shock eléctrico, ahogamientos, mutilaciones, cegar ojos, perforar tímpanos, arrancar uñas, castrar). De esta manera, el relato demuestra su esfuerzo por reconstruir los entretelones macabros del régimen, con el fin de restaurar la memoria en tanto resistencia del torturado y de la sociedad brasileña que se mantuvo pasiva. En este sentido, Betto realiza una fuerte crítica al Campeonato Mundial de Fútbol de 1970, en el que Brasil salió campeón, como un opiáceo del pueblo, una forma en la que las elites dominantes ocultaron la verdadera historia y condenaron al olvido. Motivo por el cual gran parte de la población aún desconoce estos hechos en el año 2009, año de publicación de Diario de Fernando:

"El torturador olvida fácilmente. Embotado por el oficio, es como el verdugo que, insensible, borra de la memoria el número y el semblante de sus víctimas. El torturado

\footnotetext{
22 Achugar, Hugo, "Historias paralelas/historias ejemplares...", op. cit.

23 Betto, Frei, Diário de Fernando..., op.cit., p. 81.

${ }^{24}$ Betto, Frei, Diário de Fernando..., op.cit., p. 54.
} 
jamás olvida. Su resistencia reside en la memoria. Esta no se puede borrar. No se trata de retener el recuerdo del dolor guardado en una vasija de heridas. En ese caso, la venganza es inútil, se puede punir a un torturador, jamás a la tortura y los torturadores. Por eso la memoria del dolor es subversiva. Crea la incomodidad, desenmascara a los cínicos, mantiene encendida la antorcha de la Justicia. Es el grito permanentemente detenido en el aire. No el grito de la víctima golpeada, sino de la indignación, de la reafirmación de lo humano, de la negación del terror. Grito que silencia al horror." 25

La importancia de la memoria como espacio ontológico de resistencia, también se relaciona con los espacios físicos en las que transcurre la acción. Para Claudia Feld, ${ }^{26}$ analizar testimonios y memorias supone abordarlas en tres aspectos. Un primer aspecto se relaciona con la dimensión narrativa (quién narra, cómo y para quién), otro aspecto se vincula con la "puesta en escena" de la memoria, es decir, los espacios de la memoria y sus dispositivos de representación; finalmente, un último aspecto es la dimensión veritativa, en donde lo importante es el tipo de verdad que se construye sobre el pasado y su relación con otras verdades, otras memorias.

En el relato de Betto, asistimos a verdaderos escenarios memorialísticos: las prisiones se convierten en museos de la memoria, porque Betto repone el uso originario de aquellos espacios devenidos luego en centros de tortura. El DEOPS (Departamento Estadual de Orden Político y Social) construido a comienzos del siglo XX como almacén y centro de oficinas, es en 1969 "un animal siniestro, un enorme Moloch erguido y solemne, una venerable diosa de la Seguridad Nacional, un castillo de Frankenstein". El Presidio Tiradentes, donde los presos pasan la mayor parte de su condena, se asemeja a un purgatorio antes que al infierno, y a un quilombo en tanto espacio de resistencia al no haber torturas. También Betto analiza el pasado irónico de este predio:

"irónico capricho de la elite brasileña: bautizar con el nombre de quien sacrificó la vida por la libertad a un lugar destinado a confinar cuerpos e ideas (...) cárcel edificada en 1851 en el centro de San Pablo, destinada a vagabundos y esclavos fugitivos. Sirvió también de lugar de compra y venta de esclavos para los cafetales paulistas. Se oprimió, así, el símbolo de la libertad." 27

La penitenciaria del Estado, a donde son transferidos en mayo de 1972, construida en 1922 específicamente para albergar presos, se parece a una "abadía medieval" según Betto, una especie de ciudadela erigida para albergar la opresión, y que pone en paralelo la tragedia brasileña con el genocidio judío:

“En el frontispicio de esta sarcófago de cemento, la advertencia a los que llegan: 'Aquí el trabajo, la disciplina y la bondad rescatan tu falta.' En la entrada de Auschwitz, el más terrible campo de exterminio construido por los nazis, consta la inscripción: Arbeit macht frei (El trabajo libera). Cualquier semejanza no me parece mera coincidencia...". ${ }^{28}$

El centro de detención de Carandirú, al cual son trasladados posteriormente, permite una mirada crítica sobre la continuación de ciertas prácticas durante la democracia, a través de una nota al pie que aclara que fue creada en 1950 pero que en octubre de 1992 la Policía Militar masacró a 111 presos, motivo por el cual fue clausurada en 2002. De esta forma el relato barre pasado, presente y futuro, demostrando que la historia de la sociedad brasileña está marcada por la opresión, el terror y el olvido. Esto permite aseverar la tesis que plantea Sarlo respecto de que los testimonios

\footnotetext{
${ }^{25}$ Betto, Frei, Diário de Fernando..., op.cit., p. 18.

${ }^{26}$ Feld, Claudia (y Jessica Stites Mor), El pasado que miramos: memoria e imagen ante la historia reciente, Buenos Aires, Paidós, 2009.

${ }^{27}$ Betto, Frei, Diário de Fernando..., op.cit., p. 45.

28 Betto, Frei, Diário de Fernando..., op.cit., p. 183.
} 
fundados en los hechos de los años sesenta y setenta se construyen desde el presente de escritura, es decir, juegan en el escenario de los conflictos actuales que configuran el material narrado.

Así, este paralelismo entre prisión-sociedad brasileña en el tiempo presente del relato, supone una idea del encierro mismo como exilio, en el cual interior y exterior aparecen comunicados a través de informaciones periodísticas sobre la actualidad política. A medida que crece la repercusión internacional de la represión en Brasil y del caso de los religiosos detenidos (a través de la difusión de ediciones del libro de cartas de Betto, del testimonio de las torturas sufridas por Frei Tito, noticias sobre la huelga de hambre, la intervención del Vaticano en defensa de los religiosos) el exterior ingresa al recinto cerrado de la cárcel (podría pensarse de la misma manera que el sistema represivo comienza a tener grietas en su control de la censura) y el relato acentúa su fragmentariedad con la sucesión de espacios (los prisioneros son desplazados permanentemente de celdas) y fragmentos más breves conteniendo noticias.

El exterior ingresa a la prisión a través de dos elementos: diarios y radio. Los diarios brasileños $(O$ Estadao) permanentemente citados en el cuerpo del relato para legitimar las noticias narradas, ponen en escena las versiones oficiales difundidas por el régimen. Mientras que lo no informado por éstos ingresa a la prisión a través de diarios extranjeros como Le Monde, la revista Paris Match y radios extranjeras como la BBC, Radio Habana Cuba y Radio Pekín. Empero, una serie de informaciones que ingresa al circuito interior de la prisión aparece sin fuentes precisas en tanto silenciadas por la prensa local, como casos concretos de represión hacia guerrilleros. Esto demuestra el valor que asume la circulación de información en cualquier situación de censura. De esta manera, la relación interior-exterior se expande de la relación prisión-exterior, hacia una relación mayor: Brasil dictatorial-resto del mundo democrático. En el siguiente fragmento se evidencian los tres circuitos de información:

"La Radio Moscú citó ayer, al diario francés Le Figaro, que dio noticias de la Iglesia en Brasil, en especial de San Felix de Araguaia (MT) y Dom Pedro Casaldáliga. La Radio Habana hizo lo mismo, citando al diario L'Avennire, de Italia. El Sao Paulo de 31/7 publicó una nota del obispo de Sorocaba (SP) sobre la muerte de Alexandre Vannuchi. El sábado, hubo misa en la Catedral da Sé, celebrada por 15 padres y presidida por Dom Paulo Evariso Arns. Cinco mil universitarios presentes. El cardenal profirió una homilía corajuda. Al final, Sergio Ricardo cantó 'calabouco'. Al salir de la catedral, 30 estudiantes fueron presos. ${ }^{, 29}$

Se produce un ida y vuelta entre exterior e interior y las reflexiones que merece el sistema carcelario sirven para pensar el funcionamiento de toda una sociedad bajo un sistema dictatorial, en tanto animaliza al hombre, lo condena a la ociosidad intelectual y lo aliena en su relación con él mismo y con el otro:

"En la prisión frente a tanta anormalidad, corremos el riesgo de volvernos insensibles, inhumanos, sea por el aburguesamiento, sea por la animalización. El primer riesgo es frecuente entre presos políticos; el segundo, entre comunes [...] En la pequeña área que lo abriga como una cuna macabra, su cuerpo se ve obligado a disciplinarse, privado de movilidad y voluntad. De ahí la tendencia de la imaginación a alcanzar vuelos incontenibles" ${ }^{\prime 30}$.

Esto pone en escena el propósito central de todo sistema totalitario, diluir al individuo dentro de una maquinaria colectiva en la que se le niega la posibilidad de pensamiento crítico, y en la que carece de un espacio privado invadido y manipulado por políticas de terror. El miedo instaurado por un régimen autoritario cierra espacios subjetivos, limita el movimiento, no sólo de los presos políticos, sino de todos aquellos que lo vivieron.

\footnotetext{
29 Betto, Frei, Diário de Fernando..., op.cit., p. 271.

${ }^{30}$ Betto, Frei, Diário de Fernando..., op.cit., p. 66.
} 
La idea de la prisión como metáfora de la sociedad brasileña aparece también puesta en evidencia a partir de la relación de los religiosos con los presos comunes. Si a gran escala, la Iglesia en Brasil es percibida como alentadora de la subversión, dentro de la prisión, los religiosos detenidos son mirados como mala influencia para los presos comunes:

"Sabemos que el director tiene de nosotros la siguiente imagen: Politi, inofensivo, Mané, anarquista, los Frailes, líderes intelectuales apoyados por la Iglesia, Caixe, nuestro jefe. Para las autoridades de San Pablo, además de que nosotros tres aseguramos el apoyo de la Iglesia a los presos políticos, somos los unificadores de las Organizaciones revolucionarias en la cárcel. Por eso debemos ser alejados de la capital”31.

Esta relación con los presos comunes permite que el relato reconstruya el clima ideológico de la época, en especial en torno a aquellas prácticas novedosas de la Iglesia Católica Latinoamericana, si se tiene en cuenta que el narrador(es) es un religioso vinculado al movimiento de la Teología de la Liberación. En primer lugar, el relato pone en evidencia con absoluta meticulosidad, la creciente tensión entre los sectores progresistas de la Iglesia -encarnados en el obispo Paulo Evariso Arns, Dom Helder Camara y Pedro Casaldáliga como las figuras más emblemáticas- y los sectores reaccionarios aliados al régimen militar: "La represión se pregunta si nuestra liberación no pondrá leña en la movilización antidictadura de la Iglesia Católica". ${ }^{32}$ El caso de la prisión de los dominicos acelera dicha tensión a partir del apoyo del Vaticano y de Pablo VI, lo cual a nivel textual se observa en la proliferación de noticias provenientes de medios de comunicación internacionales a través del uso del discurso directo e indirecto: “L'Osservatore Romano, órgano oficial del Vaticano, en un editorial titulado 'Firme Advertencia', afirmó que en Brasil hay 'abusos de poder' y el gobierno interfiere arbitrariamente en los asuntos de la Iglesia; agregó que el Papa sigue los acontecimientos relativos a la iglesia en el país con 'preocupación y ansiedad' (...)". ${ }^{33}$

En consecuencia, a lo largo de la narración se observa un viraje ideológico nuevo en la Iglesia brasileña que va abandonando lentamente su "indiferencia" frente a la política y comienza a asumir una posición de denuncia, cuando ya los casos de torturas se hacen insoslayables. La Iglesia se convierte así, en el último bastión de resistencia de los civiles frente a los abusos del régimen:

"La Iglesia siempre fue defensora de los derechos humanos. Donde estén los vilipendiados, ella debe hacer oír su voz. Los últimos documentos del magisterio eclesiástico dejaron muy clara esta preocupación por los más débiles: la Iglesia siempre se colocó del lado de los oprimidos y de los que sufren, contra cualquier forma de opresión y servidumbre humana. Hoy en Brasil, la Iglesia es la única institución sobre la que el gobierno no tiene control. Hoy tiene fuerza, mañana, tal vez, ya haya sido tragada por esta ola. Si la Iglesia no habla ahora, si continúa asumiendo actitudes tímidas, no hay duda de que, en breve, estaremos todos cercenados. Es impresionante sentir cómo todos los que están presos con nosotros, cristianos y no cristianos, esperan ansiosamente una actitud de la Iglesia, que consideran la última defensa posible." ${ }^{34}$

Esta opción histórica de la Iglesia por el oprimido, que se vuelve pilar de la Iglesia latinoamericana en los años setenta, ingresa a la prisión en las prácticas que comparten religiosos y presos comunes. Por ejemplo, a partir de la creación de grupos de lectura en clave política del evangelio, que reproducen las prácticas de las Comunidades de Base popularizadas en los años setenta. Eso conduce a una visión histórica de la figura de Jesús, que se identifica en el relato

\footnotetext{
${ }^{31}$ Betto, Frei, Diário de Fernando..., op.cit., p. 253.

32 Betto, Frei, Diário de Fernando..., op.cit., p. 269.

${ }_{33}$ Betto, Frei, Diário de Fernando..., op.cit., p. 131.

${ }^{34}$ Betto, Frei, Diário de Fernando..., op.cit., p. 85.
} 
permanentemente con los presos políticos. Identificación que el testimonio de Tito afirmará al compararlo con el líder revolucionario Marighella:

"Nos anima la Fe. Somos discípulos de un prisionero político -Jesús, preso, torturado y asesinado por el Imperio Romano. De las celebraciones extraemos coraje. El gesto litúrgico rompe fronteras religiosas y filosóficas. En el límite de la vida, el ser humano acata el Misterio sin interrogaciones, pleno de respeto para el silencio que encubre. Discusiones religiosas son propias de ambientes donde la razón se entrega al lujo de la ociosidad. Bajo el imperio del riesgo, la vida, planta sedienta, emerge en dirección a la luz." 35

En este pasaje también se pone en evidencia la renovación litúrgica que puso en práctica la Iglesia, y que los dominicos llevarán a cabo en las misas realizadas dentro del presidio, en donde se unen religiosos y marxistas ateos en una misma práctica, al recuperar la opción histórica de Jesús por los pobres:

"El Dios en el cual debemos creer es el de Jesús Cristo. Jesús es el Dios que se hace hombre, vivió en compañía de pobres pescadores, era amigo de lisiados y leprosos, mutilados y prostitutas, discutió con los fariseos que se creían dueños de la religión, expulsó del Templo a los que hacían comercio de la religión, fue perseguido como bandido, preso como marginal, torturado como desgraciado y muerto en la cruz." ${ }^{36}$

El relato no sólo busca legitimar una versión "contrahegemónica" de los hechos políticos, sino también reconstruir el surgimiento de ciertas prácticas que definieron históricamente a la Iglesia Latinoamericana, forzada por un escenario político de violencia e injusticia social que condujo a un replanteo ético de la función religiosa e institucional. Es decir, Betto pretende reconstruir históricamente una época fundante de la Iglesia brasileña, pero al hacerlo, lo que se busca es legitimar estos cambios a partir de un contexto político y un clima de época (auge del marxismo y de movimientos revolucionarios) que hicieron insoslayables estos cambios.

En consecuencia, si el relato testimonial pone en escena el conflicto entre verdad-ficción, entre literatura-experiencia, en términos estructurales se trata de una narración cimentada sobre la necesidad de persuasión, creados los marcos legitimantes en el ámbito público en relación a testimonios vinculados al terrorismo de Estado. Entonces, si bien es necesario que el testimonio se inserte en ciertos marcos consensuados de legitimidad documental, es necesario al mismo tiempo, que dicho relato juegue las reglas de la persuasión, en términos de un pacto de lectura que incluya fuentes primarias, junto con otras perspectivas testimoniales con fuerte impronta de la oralidad.

Frei Betto funda su relato testimonial en un objetivo de denuncia, en el cual la memoria de un hecho traumático colectivo se vuelve militancia activa en el presente a partir de una doble problemática entre la violencia de Estado y la función de la institución eclesiástica como actor político clave dentro de dicho escenario. Por ello, la pertinencia de este relato no se limita exclusivamente a engrosar la producción testimonial dedicada a los crímenes de lesa humanidad cometidos por la dictadura militar en Brasil, sino especialmente a poner en escena la mirada de la Iglesia Católica en torno a dicha conflictividad, y a justificar sus prácticas comprometidas, en especial en relación a la Iglesia brasileña que fue una de las más involucradas en la resistencia contra la dictadura. Pero particularmente teniendo en cuenta un presente de escritura en el cual aquellos impulsos reformistas fueron reabsorbidos en pos de una nueva derechización a nivel mundial de la Iglesia.

Frente a todo lo expuesto, se puede afirmar que la obra de Betto es religiosa en dos sentidos, tomando en consideración el origen etimológico de la palabra "Religión". Un primer sentido de la

35 Betto, Frei, Diário de Fernando..., op.cit., p. 66.

36 Betto, Frei, Diário de Fernando..., op.cit., p. 146. 
religión entendida como RE-LIGARE (religar) implica que se trata de un texto que busca reconstruir una totalidad a partir de la sutura de fragmentos. Betto religa los planos Pasado/Presente, Dictadura/Democracia, Vida/Muerte. Esto permite, al mismo tiempo, re-ligar la identidad latinoamericana fragmentada a partir de la idea de relato compartido (historia y memoria). En un segundo sentido de la palabra religión entendida como RE-LEGERE (releer), la obra de Betto es religiosa porque se propone como la traducción, es decir, como la relectura del relato histórico oficial a partir de la perspectiva experiencial, popular y latinoamericana. O sea, se propone como traductor de un relato "clandestino" y "perseguido" y apuesta a instalarlo en la esfera pública como lugar de disputa política. Es decir, Frei Betto vuelve a poner sobre el tapete conflictos irresueltos de la sociedad brasileña y del continente latinoamericano.

\section{Bibliografía}

Achugar, Hugo, "Historias paralelas/Historias ejemplares: la historia y la voz del otro", en Revista de Crítica Literaria Latinoamericana, 36, 1992. p. 51-73.

Antoine, Charles, L'Eglise et Le Pouvoir au Bresil: Naissance du Militarisme, París, Descleé de Bower, 1971.

Arendt, Hannah, Eichmann en Jerusalén. Un estudio sobre la banalidad del mal, Barcelona: Lumen, 1999

Betto, Frei, Diário de Fernando. Nos cárceres de ditadura militar brasileira, Rio de Janeiro, Rocco, 2009.

Betto, Frei, Entrevista realizada para la presente investigación vía correo electrónico, julio de 2013.

Cohen, Esther, Los narradores de Auschwitr, Mexico, Fineo y Limond, 2006.

Feld, Claudia (y Jessica Stites Mor), El pasado que miramos: memoria e imagen ante la historia reciente, Buenos Aires, Paidós, 2009.

Jelin, Elizabeth, "Historia, memoria social y testimonio o la legitimidad de la palabra", en Iberoamericana. América Latina - España-Portugal No 1, Volumen 1, 2001.

Sarlo, Beatriz, Tiempo pasado, Buenos Aires, Siglo XXI, 2007.

Traverso, Enzo, La historia desgarrada. Ensayo sobre Auschwitzy los intelectuales, Barcelona, Herder, 2001.

Wierviorka, Annette, L'ere du temoin, París, Hachette, 2002.

Zubieta, Ana María (comp), La memoria. Literatura, arte y política, Bahía Blanca, Ediuns, 2008. 